\title{
The Efficacy of eHealth Interventions for the Treatment of Adults Diagnosed With Full or Subthreshold Binge Eating Disorder: Systematic Review and Meta-analysis
}

Elnaz Moghimi, PhD; Caroline Davis, PhD; Michael Rotondi, PhD

School of Kinesiology and Health Science, Faculty of Health, York University, Toronto, ON, Canada

\section{Corresponding Author:}

Elnaz Moghimi, PhD

School of Kinesiology and Health Science

Faculty of Health

York University

4700 Keele Street

Toronto, ON, M3J 1P3

Canada

Phone: 14167362100 ext 77239

Email: elnazm@yorku.ca

\section{Abstract}

Background: There has been a recent rise in the use of eHealth treatments for a variety of psychological disorders, including eating disorders.

Objective: This meta-analysis of randomized controlled trials is the first to evaluate the efficacy of eHealth interventions specifically for the treatment of binge eating disorder (characterized by compulsive overconsumption of food, in a relatively short period, and without compensatory behaviors such as purging or fasting).

Methods: A search on the electronic databases PubMed, Web of Science, Embase, MEDLINE, and CINAHL was conducted for randomized controlled trials that compared the efficacy of eHealth treatment interventions with waitlist controls.

Results: From the databases searched, 3 studies (298 participants in total) met the inclusion criteria. All interventions were forms of internet-based guided cognitive behavioral therapy. The results of the analysis demonstrated that when compared with waitlist controls, individuals enrolled in eHealth interventions experienced a reduction in objective binge episodes (standardized mean difference [SMD] $-0.77,95 \% \mathrm{CI}-1.38$ to -0.16 ) and eating disorder psychopathology (SMD $-0.71,95 \% \mathrm{CI}-1.20$ to -0.22 ), which included shape (SMD -0.61, 95\% CI -1.01 to -0.22) and weight concerns (SMD -0.91, 95\% CI - 1.33 to -0.48). There was no significant difference in BMI between the eHealth interventions and controls (SMD $-0.01,95 \%$ CI -0.40 to 0.39 ).

Conclusions: These findings provide promising results for the use of internet-based cognitive behavioral therapy for binge eating disorder treatment and support the need for future research to explore the efficacy of these eHealth interventions.

(J Med Internet Res 2021;23(7):e17874) doi: 10.2196/17874

\section{KEYWORDS}

internet; cognitive behavioral therapy; guided self-help; obesity; weight loss; eating disorder; binge eating; mobile phone

\section{Introduction}

\section{Background}

Binge eating disorder (BED) is recognized in the Diagnostic and Statistical Manual of Mental Disorders as abnormal and excessive eating patterns marked by uncontrolled, recurrent, and persistent binge eating [1]. In the individual, binge eating evokes guilt and distress but without compensatory weight loss behaviors (eg, purging), such as those found in individuals with bulimia nervosa. It is the most commonly diagnosed eating disorder (ED) compared with anorexia and bulimia nervosa [2] and is estimated to have a global pooled prevalence of $0.9 \%$, with prevalence rates higher in women $(1.4 \%)$ than in men $(0.4 \%)$ [3].

BED is of particular research interest because of its frequency in primary care, its comorbidity with obesity and other medical and psychiatric disorders, and its high socioeconomic impact as a result of reduced quality of life and an increased need for 
patients to use health and medical services [4-6]. Individuals diagnosed with BED have higher inpatient, hospital-based outpatient, and prescription-medication utilization and expenditure compared with age- and sex-matched controls, both before and after their BED diagnosis [7]. The health care utilization found in patients with BED is comparable with that found in people with other EDs and major psychiatric disorders [8]. Therefore, it is imperative that effective treatments are available for these patients to help reduce health care costs and provide long-term benefits.

The current gold standard, evidence-based treatment for BED is cognitive behavioral therapy (CBT). CBT has been shown to reduce binge eating frequency, lead to mild weight reduction $[9,10]$, and cause complete abstinence in $50 \%-60 \%$ of patients post treatment [11,12]. Despite efficacious therapies available for BED, there continues to be low rates of help seeking for this debilitating mental health condition [13]. The important reasons for these trends may be the personal feelings of shame and fear, ED-related beliefs and perceptions, and a lack of access or availability of the treatment $[14,15]$. Thus, it is important that novel therapies address these barriers to treatment seeking.

Recently, the use of eHealth technology has been proposed as a potentially effective alternative to traditional, in-person treatment delivery for those with BED [16-19]. Although the term eHealth has many facets, it is generally defined as the use of emerging information and communication technology, particularly via the internet, to improve or enable health and health care [20]. Examples include, but are not limited to, email; software programs; teleconferencing or web conferencing; digital and mobile communication; and computer, mobile, or internet apps. The benefit of eHealth treatments is that they can be administered easily, are more accessible (particularly for patient groups that do not live near urban centers), can be used anonymously, and may reduce feelings of shame and fear [15]. Furthermore, eHealth treatments may be more cost-effective because in-person treatments often require expensive resources and infrastructure [15,21,22]. Although the first internet-delivered psychological treatments only emerged in the late 1990s [23], reviews exploring the effectiveness of internet-delivered treatments for EDs have yielded positive results in terms of their impact on quality of life, binge eating, compliance, dropout, and related psychopathology [24-28].
Many eHealth treatments for BED are in line with the CBT principles described in the self-help book Overcoming binge eating [29]. Some studies have described this approach as internet-based cognitive behavioral therapy (I-CBT), whereas other studies have described this approach as internet-based guided self-help (I-GSH). Both therapies consist of a combination of web-based psychoeducation, writing assignments or modules, and self-monitoring such as daily eating and activity diaries [10,30-34]. In most studied cases, I-CBT and I-GSH are typically guided to varying degrees by therapists, who provide support and answer questions and concerns that the patient may have.

\section{Objective}

Although several studies have examined the effects of eHealth treatments on different elements of BED, including bulimia [10,24,30-35], the overall effectiveness of these treatments, for this unique clinical population, has yet to be explored. Therefore, the objective of this systematic review and meta-analysis is to determine the effectiveness of eHealth treatments in adults diagnosed with full or subthreshold BED. Specifically, important hallmarks of the disorder, including binge episodes, BMI, and ED psychopathology, will be explored.

\section{Methods}

\section{Search Strategy}

PRISMA (Preferred Reporting Items for Systematic Reviews and Meta-analyses) guidelines [36] (Multimedia Appendix 1) were followed when searching the electronic databases PubMed, Web of Science, Embase, MEDLINE, and CINAHL. A combination of MeSH (Medical Subject Headings) terms and keywords that represented the terms BED and eHealth were used to develop the algorithms. Examples of terms include bing*, binge eating, web-based treatment, internet, mobile phone, smartphone, telemedicine, telehealth, and remote. Searches were performed until February 2019 and returned a total of 744 results. Articles were restricted to English and randomized controlled trials (RCTs), where possible. In addition, 2 articles were found via FasebJ and ResearchGate. A detailed outline of the literature search is presented in Figure 1. 
Figure 1. PRISMA (Preferred Reporting Items for Systematic Reviews and Meta-Analyses) flowchart outlining the selection of studies included in the meta-analysis. BED: binge eating disorder; RCT: randomized controlled trial.

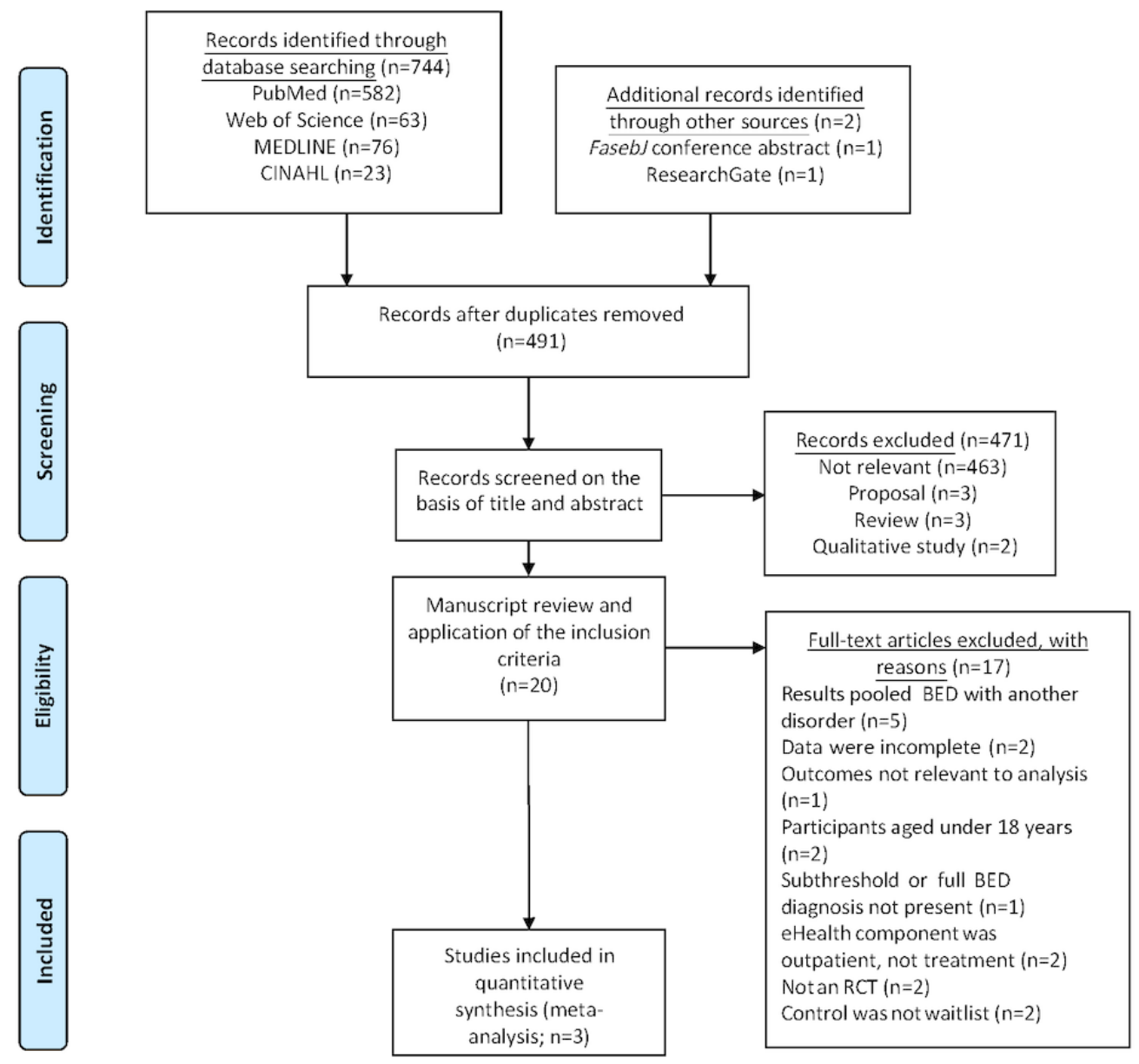

\section{Inclusion Criteria}

Studies used in the analysis had to meet the following prespecified inclusion criteria: (1) adult male or female participants aged 18 years and older, diagnosed with full or subthreshold BED. In the latter case, patients had to meet the criterion for objective binge episodes (OBEs) but could lack one of the other Diagnostic and Statistical Manual of Mental Disorders criteria (ie, frequency of less than 2 days with OBEs in 6 months, no marked distress, or presence of only 2 of the 5 associated criteria) $[1,33,37]$ (both full and subthreshold BED participants were included, as a recent study [38] showed that individuals with these conditions do not differ significantly on measures of weight and shape concerns, restraint, psychiatric distress, and history of seeking treatment for an eating or weight problem [38]); (2) the intervention was a form of eHealth treatment and was the main form of treatment and was not administered posttreatment as a form of outpatient care; (3) outcomes observed included at least one of the following: OBE, BMI, Eating Disorder Examination Questionnaire (EDE-Q) total score, EDE-Q weight concern, and EDE-Q shape concern. The EDE-Q is a self-report questionnaire that measures ED severity and consists of 4 subscales: restraint, eating concern, weight concern, and shape concern [39]. This study explores total scores and relevant subscales that are related to the cognitive-affective aspect of body image (ie, shape and weight concern), as body image disturbances are common in this population [40]; (4) included studies must be RCTs, in which participants were randomly allocated to either a treatment or control group. This was to ensure that a robust methodology was used in each study and ensure that all estimates of effectiveness were not confounded by other factors and to enable the valid pooling of the data; (5) the comparison or control group consisted of a waitlist (WL) or no treatment; and (6) mean and SD pre- and posttreatment (or data available to calculate them) were reported. Studies that analyzed BED with other disorders were excluded if they did not stratify the ED of interest. If the eHealth component was outpatient, used subsequent to another main treatment, and not the main form of treatment, the study was excluded.

\section{Data Extraction and Risk of Bias Assessment}

The following data were extracted from each study: (1) first author's last name, (2) year of publication, (3) total sample size and group size posttreatment, (4) type of treatment and control, (5) BED diagnosis status and criteria used for diagnosis, (6) mean age of participants, (7) treatment length, (8) therapist contact, (9) percentage of females in the study, and (10) mean and SD posttreatment for all outcomes in the treatment and control groups.

The overall risk of bias was assessed by 2 independent reviewers using the revised Cochrane risk of bias tool for randomized 
trials [41]. Any disagreements in the assessments were resolved via discussion. The following 5 domains were assessed: (1) bias arising from the randomization process, (2) bias due to deviations from intended interventions, (3) bias due to missing outcome data, (4) bias in outcome measurement, and (5) bias in selection of the reported result. Each study was summarized as having a low, medium, or high risk of bias (Tables 1 and 2).

Table 1. Characteristics of the studies included in the meta-analysis. Waitlist controls were compared with an internet version of cognitive behavioral therapy or guided self-help therapy. All 3 therapies use the principles of cognitive behavioral therapy and have varying degrees of therapist guidance and interaction with the patients.

\begin{tabular}{|c|c|c|c|c|c|c|c|c|c|}
\hline \multirow[t]{2}{*}{ Authors } & \multicolumn{3}{|c|}{ Participant } & \multirow{2}{*}{$\begin{array}{l}\mathrm{BED}^{\mathrm{a}} \text { diagnosis (diag- } \\
\text { nostic criteria) }\end{array}$} & \multirow[t]{2}{*}{ Therapist contact } & \multirow{2}{*}{$\begin{array}{l}\text { Females, } \\
\mathrm{n}(\%)\end{array}$} & \multirow{2}{*}{$\begin{array}{l}\text { Age, } \\
\text { mean } \\
(\mathrm{SD})\end{array}$} & \multirow{2}{*}{$\begin{array}{l}\text { Treatment } \\
\text { length }\end{array}$} & \multirow{2}{*}{$\begin{array}{l}\text { Risk of } \\
\text { bias }\end{array}$} \\
\hline & Total, $\mathrm{N}$ & $\begin{array}{l}\text { Treatment } \\
\text { group, } \mathrm{n}(\%)\end{array}$ & $\begin{array}{l}\text { Control } \\
\text { group, } \mathrm{n}(\%)\end{array}$ & & & & & & \\
\hline $\begin{array}{l}\text { Carrard et al, } \\
\text { 2011A [31] }\end{array}$ & 74 & $\begin{array}{l}37(50) \\
\mathrm{I}-G S H^{\mathrm{b}}\end{array}$ & $37(50) \mathrm{WL}^{\mathrm{c}}$ & $\begin{array}{l}\text { Full }(n=43) \text { or sub- } \\
\text { threshold }(n=31) \text { BED } \\
\text { (eating disorder ques- } \\
\text { tionnaire based on } \\
\text { DSM-IV }{ }^{d} \text { ) }\end{array}$ & $\begin{array}{l}\text { Weekly contact } \\
\text { via email }\end{array}$ & $\begin{array}{l}74 \\
(100)\end{array}$ & $\begin{array}{l}36 \\
(11.4)\end{array}$ & 6 months & Low \\
\hline $\begin{array}{l}\text { ter Huurne et al, } \\
2015 \text { [30] }\end{array}$ & 85 & $\begin{array}{l}43(51) \\
{\mathrm{I}-\mathrm{CBT}^{\mathrm{e}}}^{4}\end{array}$ & 42 (49) WL & $\begin{array}{l}\text { Diagnosed with BED } \\
\text { (participant self-report } \\
\text { based on DSM-IV) }\end{array}$ & $\begin{array}{l}\text { Internet-based } \\
\text { contact with the } \\
\text { therapist twice a } \\
\text { week }\end{array}$ & $\begin{array}{l}85 \\
(100)\end{array}$ & $\begin{array}{l}40.2 \\
(11.4)\end{array}$ & 15 weeks & Low \\
\hline
\end{tabular}

${ }^{\mathrm{a} B E D}$ : binge eating disorder.

${ }^{\mathrm{b}}$ I-GSH: internet-guided self-help.

${ }^{\mathrm{c}} \mathrm{WL}$ : waitlist.

${ }^{\mathrm{d} D S M-I V}$ : Diagnostic and Statistical Manual of Mental Disorders, 4th edition.

e I-CBT: internet-based cognitive behavioral therapy.

${ }^{\mathrm{f}}$ DSM-5: Diagnostic and Statistical Manual of Mental Disorders, 5th edition.

Table 2. Postreatment results for each study.

\begin{tabular}{|c|c|c|c|c|c|c|c|c|c|c|}
\hline \multirow[t]{2}{*}{ Authors } & \multicolumn{2}{|l|}{$\mathrm{OBE}^{\mathrm{a}}$} & \multicolumn{2}{|l|}{ BMI } & \multicolumn{2}{|l|}{$\mathrm{EDE}^{\mathrm{b}} \mathrm{Q}^{\mathrm{b}}$} & \multicolumn{2}{|c|}{ Shape concern } & \multicolumn{2}{|c|}{ Weight concern } \\
\hline & $\begin{array}{l}\text { Treatment } \\
\text { posttreat- } \\
\text { ment, mean } \\
\text { (SD) }\end{array}$ & $\begin{array}{l}\text { Control } \\
\text { posttreat- } \\
\text { ment, mean } \\
\text { (SD) }\end{array}$ & $\begin{array}{l}\text { Treatment } \\
\text { posttreat- } \\
\text { ment, mean } \\
\text { (SD) }\end{array}$ & $\begin{array}{l}\text { Control } \\
\text { posttreat- } \\
\text { ment, mean } \\
\text { (SD) }\end{array}$ & $\begin{array}{l}\text { Treatment } \\
\text { posttreat- } \\
\text { ment, mean } \\
\text { (SD) }\end{array}$ & $\begin{array}{l}\text { Control } \\
\text { posttreat- } \\
\text { ment, mean } \\
\text { (SD) }\end{array}$ & $\begin{array}{l}\text { Treatment } \\
\text { posttreat- } \\
\text { ment, mean } \\
\text { (SD) }\end{array}$ & $\begin{array}{l}\text { Control } \\
\text { posttreat- } \\
\text { ment, mean } \\
\text { (SD) }\end{array}$ & $\begin{array}{l}\text { Treatment } \\
\text { posttreat- } \\
\text { ment, mean } \\
\text { (SD) }\end{array}$ & $\begin{array}{l}\text { Control } \\
\text { posttreat- } \\
\text { ment, mean } \\
\text { (SD) }\end{array}$ \\
\hline $\begin{array}{l}\text { Carrard et al, } \\
\text { 2011A [31] }\end{array}$ & $5.5(7.4)$ & $9.1(8.8)$ & $29.2(6.0)$ & $27.9(5.4)$ & $2.5(1.1)$ & $2.9(1.0)$ & $3.7(1.3)$ & $4.1(1.3)$ & ${ }^{\mathrm{c}}$ & - \\
\hline $\begin{array}{l}\text { ter Huurne et } \\
\text { al, } 2015 \text { [30] }\end{array}$ & - & - & - & - & $2.6(1.3)$ & $3.2(0.9)$ & $3.5(1.6)$ & $4.2(1.1)$ & $3.1(1.4)$ & $3.9(0.9)$ \\
\hline $\begin{array}{l}\text { Wagner et } \\
\text { al, } 2016[10]\end{array}$ & $6.8(7.5)$ & $14.9(7.7)$ & $31.4(6.9)$ & $32.8(8.3)$ & $2.5(1.2)$ & $3.7(0.8)$ & $3.4(1.4)$ & $4.5(0.8)$ & $3.0(1.3)$ & $4.2(0.8)$ \\
\hline
\end{tabular}

aBE: objective binge episode.

${ }^{\mathrm{b}}$ EDE-Q: Eating Disorder Examination Questionnaire.

${ }^{\mathrm{c}}$ Not available (missing data).

\section{Statistical Analysis}

Given the anticipated heterogeneity, the studies were pooled using a meta-analytic random effects model. The reported $P$ values were two-sided, with $P<.05$ considered statistically significant. As all outcomes measured were continuous, means and SD were used to calculate effect size, which was expressed as a standardized mean difference (SMD), corrected using Hedges $g$ for a small sample size to reduce positive bias. The SMD was used to ensure that the scales used in the different studies were standardized. SMDs were classified based on the level of effect: less than 0.20 signified a very small effect, 0.20 
signified a small effect, 0.50 signified a medium effect, and 0.80 signified a large effect. All studies used in the analysis reported mean and SD values. The $\mathrm{I}^{2}$ statistic [42] was used to quantify between-study heterogeneity. Here, the percentage of total variation in the estimates of the effect due to between-study heterogeneity is reported [43]. $\mathrm{I}^{2}$ values above $25 \%$ indicated low heterogeneity, $50 \%$ indicated moderate heterogeneity, and above $75 \%$ indicated substantial heterogeneity [43]. The restricted maximum likelihood model estimator was used to measure the between-study variance, $\tau^{2}[44]$. Data were analyzed using the statistical software package RStudio Desktop version 1.1.463, metafor package [45].

\section{Results}

\section{Study Characteristics}

In total, 3 RCT studies met all the inclusion criteria and were included in the meta-analysis, with a total of 298 participants. All studies were consistent in the intervention and study participants and were appropriately combined in a meta-analysis. Assessment of the risk of bias scores indicated a low risk of bias in all 3 studies. Furthermore, all the studies recruited female participants, except 1 that sampled 96.4\% (134/139) females [10]. The mean age of participants ranged from 35.1 (SD 9.9) to 40.2 (SD 11.4) years. In 2 studies, all participants were diagnosed with full BED. In one study [31], participants consisted of a combination of full $(n=43)$ or subthreshold $(n=31)$ BED. Furthermore, the method of BED diagnosis varied among the studies; in 2 studies, diagnosis was made using the Diagnostic and Statistical Manual of Mental Disorders, 4th edition (DSM-IV) criteria, and in 1 study, the Diagnostic and Statistical Manual of Mental Disorders, 5th edition (DSM-5) criteria were used. Among the studies, 2 administered I-CBT as the treatment, and the other study administered an I-GSH, which also used CBT principles. Although all 3 studies were based on CBT principles, they had varying degrees of therapist contact, which ranged from weekly to any time the participant submitted an assignment. None of the studies were unguided. All the therapists in the study were clinical psychologists, except one [30] where therapists either had a Bachelor of Science in nursing or social work or a Master of Science in psychology. The studies also varied in treatment length, ranging from 15 weeks to approximately 26 weeks ( 6 months). One of the studies did not measure OBE or BMI [30], and another study did not report EDE-Q weight concern [31]. The characteristics of the included studies are summarized in Tables 1 and 2.

\section{Quantitative Analysis}

\section{Overview}

A summary of the meta-analysis results for each included outcome is described below and summarized in Table 3. Forest plots for each outcome are presented in Multimedia Appendix $2[10,30,31]$.

Table 3. Summary of findings for the randomized controlled trial studies.

\begin{tabular}{|c|c|c|c|c|c|}
\hline Outcome & Studies, n (\%) & Participants, N & Effect size; SMD ${ }^{\mathrm{a}}(95 \% \mathrm{CI})$ & Heterogeneity, $\mathrm{I}^{2 \mathrm{~b}}(\%)$ & $P$ value \\
\hline Objective binge episodes ${ }^{c}$ & $2(67)$ & 213 & $-0.77(-1.38$ to -0.16$)$ & 77 & .01 \\
\hline BMI & $2(67)$ & 213 & $-0.01(-0.40$ to 0.39$)$ & 50 & .96 \\
\hline EDE- $^{\mathrm{d}}$ total $^{\mathrm{c}}$ & $3(100)$ & 298 & $-0.71(-1.20$ to -0.22$)$ & 77 & .005 \\
\hline Shape concern ${ }^{\mathrm{c}}$ & $2(67)$ & 298 & $-0.61(-1.01$ to -0.22$)$ & 64 & .002 \\
\hline Weight concern ${ }^{c}$ & $2(67)$ & 224 & $-0.91(-1.33$ to -0.48$)$ & 56 & $<.001$ \\
\hline
\end{tabular}

${ }^{\mathrm{a}} \mathrm{SMD}$ : standardized mean difference.

${ }^{\mathrm{b}} \mathrm{I}^{2}$ values above $25 \%$ indicated low heterogeneity, $50 \%$ indicated moderate heterogeneity, and above $75 \%$ indicated substantial heterogeneity [43] ${ }^{\mathrm{c}} P<.05$.

${ }^{\mathrm{d}}$ EDE-Q: Eating Disorder Examination Questionnaire.

\section{OBE Result}

In total, 2 of the studies involving 213 participants evaluated OBE. Among the studies, one demonstrated a significant reduction in $\mathrm{OBE}$ in the treatment group compared with the WL control (SMD $-1.06,95 \% \mathrm{CI}-1.42$ to -0.70$)$. The pooled SMD was -0.77 ( $95 \%$ CI -1.38 to -0.16 ; Figure S1 of Multimedia Appendix 2 and Table 3), which showed a statistically significant effect.

\section{BMI Result}

In total, 2 of the studies involving 213 participants evaluated BMI. None of the studies demonstrated a significant change in $\mathrm{BMI}$ in the treatment group compared with the WL group. The pooled SMD was -0.01 ( $95 \%$ CI -0.40 to -0.39 ; Figure $S 2$ of Multimedia Appendix 2 and Table 3).

\section{EDE-Q Total Score}

In total, 3 of the studies involving 298 participants evaluated the EDE-Q total score. Two of the studies demonstrated a significant reduction in EDE-Q scores in the treatment group compared with WL groups (SMD $-1.17,95 \% \mathrm{CI}-1.53$ to -0.81 and SMD $-0.53,95 \% \mathrm{CI}-0.96$ to -0.10$)$. The pooled SMD was statistically significant with an estimate of -0.71 (95\% CI -1.20 to -0.22 ; Figure $S 3$ of Multimedia Appendix 2 and Table 3). 


\section{EDE-Q Shape Concern}

In total, 3 of the studies involving 298 participants evaluated the EDE-Q subscale of shape concern. Two of the studies demonstrated a significant reduction in shape concern scores in the treatment group compared with WL groups (SMD -0.96, $95 \% \mathrm{CI}-1.31$ to -0.61 and SMD $-0.50,95 \% \mathrm{CI}-0.94$ to $-0.07)$. The pooled SMD was -0.61 (95\% CI -1.01 to -0.22 ; Figure S4 of Multimedia Appendix 2 and Table 3).

\section{EDE- $Q$ Weight Concern}

In total, 2 of the studies involving 224 participants evaluated the EDE-Q subscale of weight concern. Both studies demonstrated a significant reduction in shape concern scores in the treatment group compared with WL groups (SMD -1.11, $95 \% \mathrm{CI}-1.47$ to -0.75 and SMD $-0.67,95 \% \mathrm{CI}-1.11$ to -0.23 ). The pooled SMD is -0.91 (95\% CI -1.33 to -0.48 ; Figure S5 of Multimedia Appendix 2 and Table 3).

\section{Discussion}

\section{Principal Findings}

This study reports the first meta-analysis of RCTs designed to assess the efficacy of eHealth treatments for individuals diagnosed with BED. Due to its specificity, 3 studies met the inclusion criteria and were included in the analysis. All of these used an internet-based form of guided CBT therapy, wherein the degree of therapist interaction varied depending on the nature of the intervention that was administered. Due to the novelty of eHealth innovations and our study objectives, it was important to evaluate efficacy by restricting to the RCT design. Despite the limited number of studies, statistically significant results demonstrated the effectiveness of internet-based CBT, in combination with GSH treatment, in reducing binge episodes, ED psychopathology, and shape and weight concerns. Although the efficacy of conventional CBT therapy has been well demonstrated [46-48], currently there is insufficient data to claim that internet-based CBT has an evidence base or effect size that is comparable with in-person CBT.

Despite the moderate effect of the treatment in reducing the number of OBEs, internet-based therapies did not appear to produce a significant change in BMI. Notably, the lack of substantial weight loss has long been considered one of the principal drawbacks of the current CBT therapy for BED. For instance, Peat et al [49] found no significant difference in BMI between therapist-led, partially therapist-led, and structured self-help CBT. Similarly, in a recent meta-analysis comparing pharmacological, psychological, and combined treatments, CBT was effective in reducing binge episodes, but its effect on weight loss was minimal [50]. Furthermore, the impact on BMI may be indirect, via reduced binge frequency, and consists of an extended maintenance phase [51]. In a more recent study involving in-person CBT treatment, no significant change in BMI was observed between pre- and posttreatment assessments [52]. These results are also in line with a study comparing in-person and eHealth CBT treatments, where BMI did not decrease in either treatment group, nor were they significantly different between the two groups [33]. Taken together, these

results indicate that regardless of how CBT is administered, its effects on weight loss are minimal to nonexistent.

In patients with BED, the purpose of CBT is to reduce binge eating frequency and body image dissatisfaction by altering destructive behaviors and thinking patterns, particularly those that involve eating, weight and shape, and psychosocial functioning [53]. This is in line with the findings of the current meta-analysis, where a moderate effect of the treatment in reducing shape and weight concerns was observed. There is no direct treatment emphasis on diet or weight loss. Indeed, it has been observed that eating patterns may shift from binging to less compulsive overeating, which does not have the same elements of guilt and compulsion associated with it. In this way, the caloric deficits may not be met, and consequently, BMI does not change. However, research has also found that a complete abstinence from binges is associated with significant improvements in dietary and psychological outcomes, which may improve weight status in the long term [54]. Although there was a significant reduction in binge episodes in this meta-analysis, none of the treatment studies included in this analysis resulted in complete abstinence following treatment. Interestingly, a recent study has shown that when compared with obese, non-BED participants, those diagnosed with BED have a significantly higher threshold for what comprises a large amount of food [55]. Furthermore, laboratory-based studies have also demonstrated that when compared with their non-BED counterparts, participants diagnosed with BED tend to have a significantly higher caloric intake and consume large amounts of food even during nonbinge-eating episodes [56,57].

In addition to exploring the efficacy of eHealth interventions, this meta-analysis highlights an important point regarding the status of eHealth and BED research. That is, despite its promising impact on improving BED symptomatology and its moderate effect in reducing ED psychopathology, there are only a small number of RCT studies that have evaluated the efficacy of eHealth treatments, and even fewer studies have compared them with the traditional, in-person method of delivery $[33,34]$. Specifically, only 2 other studies compared eHealth treatments with in-person therapy [33,34]. Although the efficacy of internet treatments was demonstrated in both studies, when compared with in-person treatment, one study reported inferiority [33] and the other found no significant differences between the 2 treatment types [34]. Although the results of these studies are promising, further research will provide a better understanding of the merits of internet versus in-person treatment. However, our work shows that internet treatment is efficacious and may represent a more accessible and cost-effective treatment option for those who have difficulty obtaining in-person treatment for their ED. Given that BED is the most common ED and that most individuals diagnosed do not seek treatment, it is vital for more accessible modes of treatment delivery to be assessed for their efficacy.

Despite improving the accessibility of treatment delivery, an important point that may warrant further analysis is who is administering the treatment. In this analysis, the smallest treatment effect was demonstrated in the study by ter Huurne et al [30]. Importantly, this was the only study that did not have clinical psychologists guiding the treatment. It may be that the 
specialized experience of a clinical psychologist has a stronger impact on the treatment compared with less experienced medical health professionals. However, research has determined that the efficacy of treatment, including CBT, for other mental health disorders is similar between clinical psychologists and appropriately trained medical health professionals [58-61]. It is important for future studies to determine whether these results can be generalized to patients with BED.

Since January 2019, 3 RCT study protocols have been published that outline the use of eHealth interventions for the treatment of BED $[15,62,63]$. All 3 propose using an internet-based form of CBT treatment and will use the DSM-5 criteria to diagnose BED. This is in contrast to this meta-analysis, in which of the 3 published studies, 2 used the DSM-IV criteria. One of the added benefits of using the DSM- 5 criteria is that it may also increase participant recruitment for these studies. It has already been demonstrated that many health care providers and psychiatrists have difficulty identifying BED symptoms, leading to a greater need to improve the knowledge of the diagnostic criteria for BED [64]. With the inclusion of BED as a stand-alone diagnosis and the resulting increase in awareness of the disorder, participant recruitment for these studies may increase, providing a more accurate depiction of the efficacy of these eHealth treatments. This was also a phenomenon observed in the meta-analysis; when observing the effects of individual studies, the study with the largest sample size [10] was also the one that used the DSM-5 criteria. As a result, this study also found the largest treatment effect and narrowest CIs for all outcomes when compared with the other studies used in the analysis.

\section{Limitations}

One of the limitations of this study is its level of generalizability. The majority of participants were middle-aged women who were overweight or obese. Therefore, how well these findings can be applied to other age groups and male patients is not clear. It is important to note, however, that one of the reasons why the participant pool consists primarily of overweight and obese women may be that the disorder has a higher prevalence in females, and those diagnosed are 3-6 times more likely to be obese [65]. Furthermore, the higher prevalence of the disorder in women may enhance the efficacy and use of these eHealth treatments, as women are more likely to use the internet for medical and health-related information [66]. Another limitation of the study was that despite similarities in the study designs, heterogeneity was still quite high. The heterogeneity of the outcomes BMI, shape, and weight concern were in the moderate range; however, for the outcomes OBE and EDE-Q total, their values indicated substantial heterogeneity ( $77 \%$ for both). There are several reasons why this might have occurred. First, there was considerable variability in the criteria used to diagnose BED among the studies included in the analysis. In total, 2 of the studies used the DSM-IV criteria (1 relying on participant self-report) and 1 used the DSM-5 criteria. Compared with the DSM-IV, the use of the DSM-5 yields higher prevalence rates of BED and more accurate criteria for diagnosis [67-69]. In the analysis, the only study using the DSM-5 criteria not only had a higher sample size but also the largest effect size. Second, although the CBT-I and GSH-I treatments in the study were all based on CBT principles, the treatment protocols and duration were quite different. Finally, because of the limited number of studies and the limited participant pool, the results must be interpreted with caution.

\section{Conclusions}

This study provides preliminary evidence that eHealth treatments, and more specifically internet-based guided CBT treatments, are appropriate treatment avenues for BED. However, because of the limited number of published RCTs in this field, it is important for the current evidence base to become more complete, so that more conclusive results can be extracted. As more findings are published in this area, future studies not only need to analyze the efficacy of eHealth treatments but to further hone in on the effectiveness of in-person versus eHealth treatments, to investigate the differences in efficacy among the different types of eHealth treatments, to evaluate which elements of the treatment result in unchanged BMI, and to determine the characteristics of patients with BED that make them more suitable candidates for this alternative form of treatment.

\section{Acknowledgments}

The study was conceived by EM, who conducted the literature search and quantitative analysis, wrote the first draft of the manuscript, and made subsequent revisions. CD and MR assisted with the revision of the manuscript and addition of literature references, and MR assisted with quantitative analysis. All authors have approved the submission of the manuscript.

\section{Conflicts of Interest}

EM is currently developing a mobile app that tracks psychological well-being and screens for pathological overeating in individuals who are looking to lose weight. This app is in the development phase. Although it is not a direct eHealth intervention, its tracking functionality may influence the efficacy of the treatment that the individual is undergoing. CD and MR have no conflicts of interest to declare.

\section{Multimedia Appendix 1}

PRISMA (Preferred Reporting Items for Systematic Reviews and Meta-Analyses) checklist. [DOC File , 66 KB-Multimedia Appendix 1] 


\section{Multimedia Appendix 2}

Forest plot of outcomes.

[DOCX File , 6567 KB-Multimedia Appendix 2]

\section{References}

1. American Psychiatric Association. Diagnostic and Statistical Manual of Mental Disorders, Fifth Edition. Washington: American Psychiatric Association; 2013.

2. Hudson JI, Hiripi E, Pope HG, Kessler RC. The prevalence and correlates of eating disorders in the National Comorbidity Survey Replication. Biol Psychiatry 2007 Feb 01;61(3):348-358 [FREE Full text] [doi: 10.1016/j.biopsych.2006.03.040] [Medline: 16815322]

3. Erskine HE, Whiteford HA. Epidemiology of binge eating disorder. Curr Opin Psychiatry 2018 Nov;31(6):462-470. [doi: 10.1097/YCO.0000000000000449] [Medline: 30113324]

4. Wang YC, McPherson K, Marsh T, Gortmaker SL, Brown M. Health and economic burden of the projected obesity trends in the USA and the UK. Lancet 2011 Aug 27;378(9793):815-825. [doi: 10.1016/S0140-6736(11)60814-3] [Medline: 21872750]

5. Amianto F, Lavagnino L, Abbate-Daga G, Fassino S. The forgotten psychosocial dimension of the obesity epidemic. Lancet 2011 Nov 19;378(9805):e8. [doi: 10.1016/S0140-6736(11)61778-9] [Medline: 22098857]

6. Amianto F, Ottone L, Abbate Daga G, Fassino S. Binge-eating disorder diagnosis and treatment: a recap in front of DSM-5. BMC Psychiatry 2015 Apr 03;15:70 [FREE Full text] [doi: 10.1186/s12888-015-0445-6] [Medline: 25885566]

7. Watson HJ, Jangmo A, Smith T, Thornton LM, von Hausswolff-Juhlin Y, Madhoo M, et al. A register-based case-control study of health care utilization and costs in binge-eating disorder. J Psychosom Res 2018 May;108:47-53 [FREE Full text] [doi: 10.1016/j.jpsychores.2018.02.011] [Medline: 29602325]

8. Ágh T, Kovács G, Supina D, Pawaskar M, Herman BK, Vokó Z, et al. A systematic review of the health-related quality of life and economic burdens of anorexia nervosa, bulimia nervosa, and binge eating disorder. Eat Weight Disord 2016 Sep;21(3):353-364 [FREE Full text] [doi: 10.1007/s40519-016-0264-x] [Medline: 26942768]

9. Ricca V, Castellini G, Mannucci E, Lo Sauro C, Ravaldi C, Rotella CM, et al. Comparison of individual and group cognitive behavioral therapy for binge eating disorder. A randomized, three-year follow-up study. Appetite 2010 Dec;55(3):656-665. [doi: 10.1016/j.appet.2010.09.019] [Medline: 20870000]

10. Wagner B, Nagl M, Dölemeyer R, Klinitzke G, Steinig J, Hilbert A, et al. Randomized controlled trial of an internet-based cognitive-behavioral treatment program for binge-eating disorder. Behav Ther 2016 Jul;47(4):500-514. [doi:

10.1016/j.beth.2016.01.006] [Medline: 27423166]

11. Wilson GT. Treatment of binge eating disorder. Psychiatr Clin North Am 2011 Dec;34(4):773-783. [doi: 10.1016/j.psc.2011.08.011] [Medline: 22098803]

12. McElroy SL, Guerdjikova AI, Mori N, Munoz MR, Keck PE. Overview of the treatment of binge eating disorder. CNS Spectr 2015 Dec;20(6):546-556. [doi: 10.1017/S1092852915000759] [Medline: 26594849]

13. Coffino JA, Udo T, Grilo CM. Rates of help-seeking in US adults with lifetime DSM-5 eating disorders: prevalence across diagnoses and differences by sex and ethnicity/race. Mayo Clin Proc 2019 Aug;94(8):1415-1426 [FREE Full text] [doi: 10.1016/j.mayocp.2019.02.030] [Medline: 31324401]

14. Regan P, Cachelin FM, Minnick AM. Initial treatment seeking from professional health care providers for eating disorders: a review and synthesis of potential barriers to and facilitators of "first contact". Int J Eat Disord 2017 Mar;50(3):190-209. [doi: 10.1002/eat.22683] [Medline: 28134980]

15. Munsch S, Wyssen A, Vanhulst P, Lalanne D, Steinemann ST, Tuch A. Binge-eating disorder treatment goes online feasibility, usability, and treatment outcome of an Internet-based treatment for binge-eating disorder: study protocol for a three-arm randomized controlled trial including an immediate treatment, a waitlist, and a placebo control group. Trials 2019 Feb 13;20(1):128 [FREE Full text] [doi: 10.1186/s13063-019-3192-z] [Medline: 30760299]

16. Hamatani S, Numata N, Matsumoto K, Sutoh C, Ibuki H, Oshiro K, et al. Internet-based cognitive behavioral therapy via videoconference for patients with bulimia nervosa and binge-eating disorder: pilot prospective single-arm feasibility trial. JMIR Form Res 2019 Oct 23;3(4):e15738 [FREE Full text] [doi: 10.2196/15738] [Medline: $\underline{31647472]}$

17. Yim SH, Schmidt U. Experiences of computer-based and conventional self-help interventions for eating disorders: a systematic review and meta-synthesis of qualitative research. Int J Eat Disord 2019 Oct;52(10):1108-1124. [doi: 10.1002/eat.23142] [Medline: 31343088 ]

18. Yim SH, Bailey E, Gordon G, Grant N, Musiat P, Schmidt U. Exploring participants' experiences of a web-based program for bulimia and binge eating disorder: qualitative study. J Med Internet Res 2020 Sep 23;22(9):e17880 [FREE Full text] [doi: 10.2196/17880] [Medline: 32965235]

19. Moghimi E, Davis CA, Rotondi M. eHealth treatments for compulsive overeating: a narrative review. Curr Addict Rep 2020 Sep 01;7(3):395-404. [doi: 10.1007/s40429-020-00312-0]

20. Eng TR. Population health technologies: emerging innovations for the health of the public. Am J Prev Med 2004 Apr;26(3):237-242 [FREE Full text] [doi: 10.1016/j.amepre.2003.12.004] [Medline: 15026105] 
21. König H, Bleibler F, Friederich H, Herpertz S, Lam T, Mayr A, et al. Economic evaluation of cognitive behavioral therapy and internet-based guided self-help for binge-eating disorder. Int J Eat Disord 2018 Feb;51(2):155-164. [doi: 10.1002/eat.22822] [Medline: 29345848]

22. Watson HJ, McLagan N, Zerwas SC, Crosby RD, Levine MD, Runfola CD, et al. Cost-effectiveness of internet-based cognitive-behavioral treatment for bulimia nervosa: results of a randomized controlled trial. J Clin Psychiatry 2018;79(1):11314 [FREE Full text] [doi: 10.4088/JCP.16m11314] [Medline: 29228517]

23. Andersson G, Carlbring P, Ljótsson B, Hedman E. Guided internet-based CBT for common mental disorders. J Contemp Psychother 2013 May 21;43(4):223-233. [doi: 10.1007/s10879-013-9237-9]

24. Aardoom JJ, Dingemans AE, Spinhoven P, Van Furth EF. Treating eating disorders over the internet: a systematic review and future research directions. Int J Eat Disord 2013 Sep;46(6):539-552. [doi: 10.1002/eat.22135] [Medline: 23674367]

25. Sadeh-Sharvit S, Kim JP, Darcy AM, Neri E, Vierhile M, Robinson A, et al. Subgrouping the users of a specialized app for eating disorders. Eat Disord 2018;26(4):361-372. [doi: 10.1080/10640266.2018.1440043] [Medline: 29452025]

26. Shingleton RM, Richards LK, Thompson-Brenner H. Using technology within the treatment of eating disorders: a clinical practice review. Psychotherapy (Chic) 2013 Dec;50(4):576-582 [FREE Full text] [doi: 10.1037/a0031815] [Medline: 23527906]

27. Loucas CE, Fairburn CG, Whittington C, Pennant ME, Stockton S, Kendall T. E-therapy in the treatment and prevention of eating disorders: a systematic review and meta-analysis. Behav Res Ther 2014 Dec;63:122-131 [FREE Full text] [doi: 10.1016/j.brat.2014.09.011] [Medline: 25461787]

28. Pittock A, Hodges L, Lawrie SM. The effectiveness of internet-delivered cognitive behavioural therapy for those with bulimic symptoms: a systematic review : a review of iCBT treatment for bulimic symptoms. BMC Res Notes 2018 Oct 22;11(1):748 [FREE Full text] [doi: 10.1186/s13104-018-3843-2] [Medline: 30348226]

29. Fairburn C. Overcoming Binge Eating. New York, United States: The Guilford Press; 1995:1-247.

30. ter Huurne ED, de Haan HA, Postel MG, van der Palen J, VanDerNagel JE, DeJong CA. Web-based cognitive behavioral therapy for female patients with eating disorders: randomized controlled trial. J Med Internet Res 2015 Jun 18;17(6):e152 [FREE Full text] [doi: 10.2196/jmir.3946] [Medline: 26088580]

31. Carrard I, Crépin C, Rouget P, Lam T, Golay A, Van der Linden M. Randomised controlled trial of a guided self-help treatment on the internet for binge eating disorder. Behav Res Ther 2011 Aug;49(8):482-491. [doi: 10.1016/j.brat.2011.05.004] [Medline: 21641580]

32. Carrard I, Crépin C, Rouget P, Lam T, Van der Linden M, Golay A. Acceptance and efficacy of a guided internet self-help treatment program for obese patients with binge eating disorder. Clin Pract Epidemiol Ment Health 2011;7:8-18 [FREE Full text] [doi: 10.2174/1745017901107010008] [Medline: 21552482]

33. de Zwaan M, Herpertz S, Zipfel S, Svaldi J, Friederich H, Schmidt F, et al. Effect of internet-based guided self-help vs individual face-to-face treatment on full or subsyndromal binge eating disorder in overweight or obese patients: the INTERBED randomized clinical trial. JAMA Psychiatry 2017 Oct 01;74(10):987-995. [doi:

10.1001/jamapsychiatry.2017.2150] [Medline: 28768334]

34. Shapiro JR, Reba-Harrelson L, Dymek-Valentine M, Woolson SL, Hamer RM, Bulik CM. Feasibility and acceptability of CD-ROM-based cognitive-behavioural treatment for binge-eating disorder. Eur Eat Disord Rev 2007 May;15(3):175-184. [doi: 10.1002/erv.787] [Medline: 17676687]

35. Juarascio AS, Goldstein SP, Manasse SM, Forman EM, Butryn ML. Perceptions of the feasibility and acceptability of a smartphone application for the treatment of binge eating disorders: qualitative feedback from a user population and clinicians. Int J Med Inform 2015 Oct;84(10):808-816 [FREE Full text] [doi: 10.1016/j.ijmedinf.2015.06.004] [Medline: 26113461]

36. Moher D, Liberati A, Tetzlaff J, Altman DG, PRISMA Group. Preferred reporting items for systematic reviews and meta-analyses: the PRISMA statement. Br Med J 2009 Jul 21;339:b2535 [FREE Full text] [doi: 10.1136/bmj.b2535] [Medline: 19622551]

37. American Psychiatric Association. Diagnostic and Statistical Manual of Mental Disorders, Fourth Edition. Washington: American Psychiatric Association; 1994.

38. Striegel-Moore RH, Dohm FA, Solomon EE, Fairburn CG, Pike KM, Wilfley DE. Subthreshold binge eating disorder. Int J Eat Disord 2000 Apr;27(3):270-278. [doi: 10.1002/(sici)1098-108x(200004)27:3<270::aid-eat3>3.0.co;2-1] [Medline: 10694712]

39. Fairburn C, Cooper Z, O'Connor M. Eating disorder examination. In: Fairburn CG, editor. Cognitive Behavior Therapy and Eating Disorders. New York, United States: The Guilford Press; 2008:265-308.

40. Lewer M, Kosfelder J, Michalak J, Schroeder D, Nasrawi N, Vocks S. Effects of a cognitive-behavioral exposure-based body image therapy for overweight females with binge eating disorder: a pilot study. J Eat Disord 2017;5:43 [FREE Full text] [doi: 10.1186/s40337-017-0174-y] [Medline: 29296280]

41. Sterne JA, Savović J, Page MJ, Elbers RG, Blencowe NS, Boutron I, et al. RoB 2: a revised tool for assessing risk of bias in randomised trials. Br Med J 2019 Aug 28;366:14898. [doi: 10.1136/bmj.14898] [Medline: $\underline{31462531]}$

42. Higgins JPT, Thompson SG. Quantifying heterogeneity in a meta-analysis. Stat Med 2002 Jun 15;21(11):1539-1558. [doi: 10.1002/sim.1186] [Medline: 12111919] 
43. Higgins JP, Thompson SG, Deeks JJ, Altman DG. Measuring inconsistency in meta-analyses. Br Med J 2003 Sep 6;327(7414):557-560 [FREE Full text] [doi: 10.1136/bmj.327.7414.557] [Medline: 12958120 ]

44. Veroniki AA, Jackson D, Viechtbauer W, Bender R, Bowden J, Knapp G, et al. Methods to estimate the between-study variance and its uncertainty in meta-analysis. Res Synth Methods 2016 Mar;7(1):55-79 [FREE Full text] [doi: 10.1002/jrsm.1164] [Medline: 26332144]

45. Viechtbauer W. Conducting meta-analyses in R with the metafor package. J Stat Soft 2010;36(3):1-48. [doi: 10.18637/jss.v036.i03]

46. Hilbert A, Petroff D, Herpertz S, Pietrowsky R, Tuschen-Caffier B, Vocks S, et al. Meta-analysis on the long-term effectiveness of psychological and medical treatments for binge-eating disorder. Int J Eat Disord 2020 Sep;53(9):1353-1376. [doi: 10.1002/eat.23297] [Medline: 32583527]

47. Hilbert A, Petroff D, Herpertz S, Pietrowsky R, Tuschen-Caffier B, Vocks S, et al. Meta-analysis of the efficacy of psychological and medical treatments for binge-eating disorder. J Consult Clin Psychol 2019 Jan;87(1):91-105. [doi: 10.1037/ccp0000358] [Medline: 30570304]

48. Traviss-Turner GD, Philpot U, Wilton J, Green K, Heywood-Everett S, Hill AJ. Guided self-help to manage binge eating in a dietetic-led community weight management service. Clin Obes 2018 Aug;8(4):250-257. [doi: 10.1111/cob.12259] [Medline: 29900680]

49. Peat CM, Berkman ND, Lohr KN, Brownley KA, Bann CM, Cullen K, et al. Comparative effectiveness of treatments for binge-eating disorder: systematic review and network meta-analysis. Eur Eat Disord Rev 2017 Sep;25(5):317-328. [doi: 10.1002/erv.2517] [Medline: 28467032]

50. Ghaderi A, Odeberg J, Gustafsson S, Råstam M, Brolund A, Pettersson A, et al. Psychological, pharmacological, and combined treatments for binge eating disorder: a systematic review and meta-analysis. PeerJ 2018;6:e5113 [FREE Full text] [doi: 10.7717/peerj.5113] [Medline: 29942715]

51. Cooper Z, Calugi S, Grave R. Controlling binge eating and weight: a treatment for binge eating disorder worth researching? Eat Weight Disord 2020 Aug;25(4):1105-1109. [doi: 10.1007/s40519-019-00734-4] [Medline: 31214963]

52. Quilty LC, Allen TA, Davis C, Knyahnytska Y, Kaplan AS. A randomized comparison of long acting methylphenidate and cognitive behavioral therapy in the treatment of binge eating disorder. Psychiatry Res 2019 Mar;273:467-474. [doi: 10.1016/j.psychres.2019.01.066] [Medline: 30684794]

53. Brownley KA, Berkman ND, Sedway JA, Lohr KN, Bulik CM. Binge eating disorder treatment: a systematic review of randomized controlled trials. Int J Eat Disord 2007 May;40(4):337-348. [doi: 10.1002/eat.20370] [Medline: 17370289]

54. Masheb RM, Dorflinger LM, Rolls BJ, Mitchell DC, Grilo CM. Binge abstinence is associated with reduced energy intake after treatment in patients with binge eating disorder and obesity. Obesity (Silver Spring) 2016 Dec;24(12):2491-2496 [FREE Full text] [doi: 10.1002/oby.21664] [Medline: 27797154]

55. Chao AM, Wadden TA, Walsh OA, Gruber KA, Alamuddin N, Berkowitz RI, et al. Perceptions of a large amount of food based on binge-eating disorder diagnosis. Int J Eat Disord 2019 Jul;52(7):801-808 [FREE Full text] [doi: 10.1002/eat.23076] [Medline: $\underline{\text { 30927476] }}$

56. Yanovski SZ, Leet M, Yanovski JA, Flood M, Gold PW, Kissileff HR, et al. Food selection and intake of obese women with binge-eating disorder. Am J Clin Nutr 1992 Dec;56(6):975-980. [doi: 10.1093/ajcn/56.6.975] [Medline: 1442665]

57. Walsh BT, Boudreau G. Laboratory studies of binge eating disorder. Int J Eat Disord 2003;34 Suppl:30-38. [doi: 10.1002/eat.10203] [Medline: 12900984]

58. van Boeijen CA, van Oppen P, van Balkom AJ, Visser S, Kempe PT, Blankenstein N, et al. Treatment of anxiety disorders in primary care practice: a randomised controlled trial. Br J Gen Pract 2005 Oct;55(519):763-769 [FREE Full text] [Medline: 16212851]

59. Shandley K, Austin DW, Klein B, Pier C, Schattner P, Pierce D, et al. Therapist-assisted, internet-based treatment for panic disorder: can general practitioners achieve comparable patient outcomes to psychologists? J Med Internet Res 2008;10(2):e14 [FREE Full text] [doi: 10.2196/jmir.1033] [Medline: 18487138]

60. Høifødt RS, Strøm C, Kolstrup N, Eisemann M, Waterloo K. Effectiveness of cognitive behavioural therapy in primary health care: a review. Fam Pract 2011 Oct;28(5):489-504 [FREE Full text] [doi: 10.1093/fampra/cmr017] [Medline: 21555339]

61. Hiltunen AJ, Kocys E, Perrin-Wallqvist R. Effectiveness of cognitive behavioral therapy: an evaluation of therapies provided by trainees at a university psychotherapy training center. Psych J 2013 Aug;2(2):101-112 [FREE Full text] [doi: 10.1002/pchj.23] [Medline: 24436779]

62. Anastasiadou D, Lupiañez-Villanueva F, Faulí C, Cunillera J, Serrano-Troncoso E. Cost-effectiveness of the mobile application TCApp combined with face-to-face CBT treatment compared to face-to-face CBT treatment alone for patients with an eating disorder: study protocol of a multi-centre randomised controlled trial. BMC Psychiatry 2018 May 02;18(1):118 [FREE Full text] [doi: 10.1186/s12888-018-1664-4] [Medline: 29716580]

63. Vollert B, Beintner I, Musiat P, Gordon G, Görlich D, Nacke B, et al. Using internet-based self-help to bridge waiting time for face-to-face outpatient treatment for bulimia nervosa, binge eating disorder and related disorders: study protocol of a randomized controlled trial. Internet Interv 2019 Apr;16:26-34 [FREE Full text] [doi: 10.1016/j.invent.2018.02.010] [Medline: 30775262] 
64. Chao AM, Rajagopalan AV, Tronieri JS, Walsh O, Wadden TA. Identification of binge eating disorder criteria: results of a national survey of healthcare providers. J Nurs Scholarsh 2019 Jul;51(4):399-407 [FREE Full text] [doi: 10.1111/jnu.12468] [Medline: $\underline{30821428}$ ]

65. Kessler RC, Berglund PA, Chiu WT, Deitz AC, Hudson JI, Shahly V, et al. The prevalence and correlates of binge eating disorder in the World Health Organization World Mental Health Surveys. Biol Psychiatry 2013 May 01;73(9):904-914 [FREE Full text] [doi: 10.1016/j.biopsych.2012.11.020] [Medline: 23290497]

66. Smail-Crevier R, Powers G, Noel C, Wang J. Health-related internet usage and design feature preference for e-mental health programs among men and women. J Med Internet Res 2019 Mar 18;21(3):e11224 [FREE Full text] [doi: 10.2196/11224] [Medline: 30882361$]$

67. Udo T, Grilo CM. Prevalence and correlates of DSM-5-defined eating disorders in a nationally representative sample of U.S. adults. Biol Psychiatry 2018 Sep 01;84(5):345-354 [FREE Full text] [doi: 10.1016/j.biopsych.2018.03.014] [Medline: 29859631]

68. Cossrow N, Pawaskar M, Witt EA, Ming EE, Victor TW, Herman BK, et al. Estimating the prevalence of binge eating disorder in a community sample from the United States: comparing DSM-IV-TR and DSM-5 criteria. J Clin Psychiatry 2016 Aug;77(8):968-974 [FREE Full text] [doi: 10.4088/JCP.15m10059] [Medline: 27232527]

69. Hudson JI, Coit CE, Lalonde JK, Pope HG. By how much will the proposed new DSM-5 criteria increase the prevalence of binge eating disorder? Int J Eat Disord 2012 Jan;45(1):139-141. [doi: 10.1002/eat.20890] [Medline: 22170026]

\author{
Abbreviations \\ BED: binge eating disorder \\ CBT: cognitive behavioral therapy \\ DSM-IV: Diagnostic and Statistical Manual of Mental Disorders, 4th edition \\ DSM-5: Diagnostic and Statistical Manual of Mental Disorders, 5th edition \\ ED: eating disorder \\ EDE-Q: Eating Disorder Examination Questionnaire \\ I-CBT: internet-based cognitive behavioral therapy \\ I-GSH: internet-based guided self-help \\ MeSH: Medical Subject Headings \\ OBE: objective binge episode \\ PRISMA: Preferred Reporting Items for Systematic Reviews and Meta-analyses \\ RCT: randomized controlled trial \\ SMD: standardized mean difference \\ WL: waitlist
}

Edited by R Kukafka; submitted 20.01.20; peer-reviewed by A Martinez-Millana, DM Liou, B Taylor; comments to author 06.09.20;
revised version received 18.12.20; accepted 13.05.21; published 20.07.21
Please cite as:
Moghimi E, Davis C, Rotondi $M$
The Efficacy of eHealth Interventions for the Treatment of Adults Diagnosed With Full or Subthreshold Binge Eating Disorder:
Systematic Review and Meta-analysis
J Med Internet Res $2021 ; 23(7):$ e17874
URL: $\underline{\text { https://www.jmir.org/2021/7/e17874 }}$
doi: $10.2196 / 17874$
PMID: $\underline{34283028}$

CElnaz Moghimi, Caroline Davis, Michael Rotondi. Originally published in the Journal of Medical Internet Research (https://www.jmir.org), 20.07.2021. This is an open-access article distributed under the terms of the Creative Commons Attribution License (https://creativecommons.org/licenses/by/4.0/), which permits unrestricted use, distribution, and reproduction in any medium, provided the original work, first published in the Journal of Medical Internet Research, is properly cited. The complete bibliographic information, a link to the original publication on https://www.jmir.org/, as well as this copyright and license information must be included. 